\section{Comparison of visual outcomes, photopic contrast sensitivity, wavefront analysis, and patient satisfaction following cataract extraction and IOL implantation: aspheric vs spherical acrylic lenses}

HP Sandoval, LE Fernández de Castro, DT Vroman and KD Solomon
Magill Research Center for Vision Correction, Storm Eye Institute, Medical University of South Carolina, Charleston, SC, USA

Correspondence: HP Sandoval, Magill Research Center for Vision Correction, MUSC-Storm Eye Institute, 167 Ashley Avenue, Charleston, SC 29425, USA Tel: 843792 2305;

Fax: 8437926347

E-mail: sandoval@musc.edu

Received: 14 February 2007 Accepted in revised form: 5 June 2007 Published online: 6 July 2007

Presented in part at the annual meeting of the American Society of Cataract and Refractive Surgery, San Francisco, CA, USA, 17-22 March 2006 
cataract surgery and IOL implantation, ${ }^{1}$ which can be influenced by optic design, dimension, and spectral transmission characteristics, all optical qualities of the IOL.

Wavefront analysis is currently used to measure aberrations of the entire optical system. This technology is widely used in corneal refractive surgery, with successful outcomes. With the introduction of wavefront analysis, a new tool is available to re-design and study the performance of IOLs. The goal is to improve the optical quality of pseudophakic eyes, therefore, improving patients' quality of life.

The purpose of this study is to compare the quality of vision provided by two different acrylic IOLs, an aspheric IOL (AcrysofIQ SN60WF, Alcon Laboratories, Ft. Worth, TX, USA) and a spherical IOL (AcrysofSinglePiece SA60AT, Alcon Laboratories, Ft. Worth, TX, USA), implanted after routine cataract extraction by (1) determining differences in spherical aberration (SA) and other high-order aberrations (HOA), (2) establishing differences in photopic contrast sensitivity, and (3) evaluating a subjective questionnaire.

\section{Patients and methods}

This prospective randomized, double-masked study included patients $\geqslant 50$ years of age, undergoing bilateral phacoemulsification with primary implantation of a posterior-chamber IOL with a naturally dilated pupil (in dim light) $\geqslant 4.0 \mathrm{~mm}$ in both the eyes. Exclusion criteria included any preoperative ocular pathology potentially affecting visual outcome, previous intraocular or corneal surgery, keratometric astigmatism exceeding 1.5 diopters (D), planned postoperative refraction for monovision, and/or other ocular surgery at the time of the cataract extraction. Intraoperative exclusion criteria included significant anterior chamber bleeding, iris damage, detached Descemet's membrane, posterior capsule rupture, vitreous loss, and zonular rupture. Postoperative exclusion criteria included IOL decentration of more than $1.0 \mathrm{~mm}$ (evaluated by retroillumination and digital photograph), use of corneal sutures for more than 1 week, and ocular pathologies potentially affecting visual acuity that were not evident before surgery. The Medical University of South Carolina, Institutional Review Board approved this study. Informed consent was obtained from all patients after a thorough explanation of the procedure and its potential benefits and risks.

\section{Measurements and evaluations}

ETDRS (early treatment of diabetic retinopathy study) best-corrected visual acuity (BCVA), best distance-corrected photopic contrast sensitivity testing
(CSV-1000E, Vector Vision, Arcanum, OH, USA), pupil size (Colvard pupillometer, Oasis Medical Inc, Glendora, CA, USA), cataract density classification based primarily on the colour of nucleus as follows soft nuclei (Grade 1), semisoft nuclei (Grade 2), medium nuclei (Grade 3), hard nuclei (Grade 4), and rock-hard nuclei (Grade 5), wavefront testing under pharmacological mydriasis (LADARWave, Alcon Laboratories, Ft. Worth, TX, USA), and a subjective questionnaire (VFQ-39, National Eye Institute Visual Function Questionnaire) were evaluated preoperatively, 1 and 3 months postoperatively.

Patients were randomly divided into two groups using a simple 1:1 randomization ratio scheme to have the same IOL implanted in both the eyes: AcrysofIQ group or AcrysofSingle-Piece group. Both studied lenses are hydrophobic, acrylic, monofocal, and single piece IOLs. Postoperative target refraction was plano in both the groups. All surgeries were performed by the same surgeon (KDS) under topical anaesthesia, using his preferred phacoemulsification technique with an interval between first and second eye surgery of 1-4 weeks. All patients were treated preoperatively with $0.3 \%$ gatifloxacin (Zymar, Allergan, Irvine, CA, USA) and $0.4 \%$ ketorolac tromethamine ophthalmic solutions (Acular LS, Allergan, Irvine, CA, USA) topically four times per day, starting 3 days before surgery. The standard postoperative treatment used in all patients included $0.3 \%$ gatifloxacin (four times a day for a week and discontinued), $1 \%$ prednisolone acetate ophthalmic suspension (Pred Forte, Allergan, Irvine, CA, USA), and $0.4 \%$ ketorolac tromethamine (four times a day for a week, then tapered to twice a day for a month or until finished).

\section{Statistical methods}

The sample size calculated for a 0.05 level of significance with $80 \%$ power, based on a SA standard deviation of 0.18 and a minimal SA difference of 0.20 was 14 subjects per group. A minimal difference of $0.20 \mu \mathrm{m}$ was used because the AcrysofIQ IOL provides that amount of negative SA. Additionally, studies have reported that negative SA of the youthful lens ranges from -0.138 to $-0.24 \mu \mathrm{m} .^{2,3}$ Statistical analyses was performed using SAS 9.0 (SAS Institute Inc, Cary, NC, USA). Visual acuity was analyzed using the logarithm of the minimum angle of resolution (log MAR). The base $10 \log$ of the contrast sensitivity results obtained was calculated for statistical analysis. Clinical significance of contrast sensitivity was determined using a difference in level of $0.15 \mathrm{log}$ units at a given spatial frequency based on the contrast step between each grating patch. Change in contrast sensitivity was calculated by subtracting the preoperative value from the postoperative value at 1 and 
3 months. Aberrations were analysed using a $5 \mathrm{~mm}$ pupil size. Normally distributed data was analysed using the Student's $t$-test, while the Wilcoxon signed-rank test was used for non-normally distributed data. Postoperative comparisons to preoperative values within the groups were performed with the Kruskal-Wallis test. Proportions were analysed using $\chi^{2} . P<0.05$ was considered statistically significant. All $P$ values are reported two-sided.

\section{Results}

A total of 30 patients were enrolled. Three patients withdrew informed consent after randomization, but before surgery, one patient from the AcrysofIQ group and two patients from the AcrysofSingle-Piece. Additionally, one patient from the AcrysofSingle-Piece group relocated; therefore, he withdrew informed consent for the second eye after the first eye surgery, but completed the follow-up for the operated eye. All surgeries were uneventful with IOL centred in the capsular bag. None of the patients was excluded because of intraoperative or postoperative complications in either group. The total number of eyes available for analysis were 28 ( $n=14$ patients) for the AcrysofIQ group and 25 ( $n=13$ patients) for the AcrysofSingle-Piece group. Table 1 summarizes the mean preoperative patient demographics; no significant differences were found between the groups.

Mean IOL power in the AcrysofIQ group was 21.0 D (range: $16.5-25.5 \mathrm{D}$ ) and $20.1 \mathrm{D}$ (range: $10.0-27.0 \mathrm{D}$ ) in the AcrysofSingle-Piece group. At month $1,82.1 \%$ of eyes (23 out of 28 ) and $48.0 \%$ of eyes (12 out of 25 ) in the AcrysofIQ and AcrysofSingle-Piece groups, respectively, had an uncorrected visual acuity (UCVA) of 20/20.

However, $100 \%$ of eyes in both the groups were $20 / 50$ or better. Visual acuity variable at 3 months showed 24 of 28 eyes (85.7\%) in the AcrysofIQ group and 19 of 25 eyes (76.0\%) in the AcrysofSingle-Piece were 20/20 uncorrected.

The change in manifest refraction spherical equivalent (MRSE) was within $0.50 \mathrm{D}$ due to emmetropia in 26 of 28 eyes (92.8\%) in the AcrysofIQ and in 16 of 25 eyes (64.0\%) in the AcrysofSingle-Piece at 1 month, and within $1.0 \mathrm{D}$ from emmetropia in 28 of 28 eyes $(100 \%)$ and in 23 of 25 eyes $(92.0 \%)$ in the AcrysofIQ and AcrysofSingle-Piece groups, respectively. These results remained the same at 3 months in the AcrysofIQ group and improved in the AcrysofSingle-Piece group to $73 \%$ within $0.50 \mathrm{D}$ and $100 \%$ within $1.0 \mathrm{D}$. Mean MRSE at 1 month was $-0.12 \mathrm{D}$ and $-0.30 \mathrm{D}$ in the AcrysofIQ and AcrysofSingle-Piece groups, respectively ( $P=0.648$, Wilcoxon rank-sum test). At 3 months, the mean MRSE was $-0.09 \mathrm{D}$ in the AcrysofIQ and $-0.31 \mathrm{D}$ in the AcrysofSingle-Piece group
Table 1 Mean preoperative patient demographics

\begin{tabular}{|c|c|c|c|}
\hline & $\begin{array}{c}\text { AcrysofiQ }(\mathrm{n}=28 \\
\text { eyes })\end{array}$ & $\begin{array}{l}\text { AcrysofSingle-Piece } \\
\quad(\mathrm{n}=25 \text { eyes })\end{array}$ & $\begin{array}{c}\mathrm{P}- \\
\text { value }\end{array}$ \\
\hline Age & $70.7 \pm 8.8$ & $69.5 \pm 5.2$ & 0.281 \\
\hline \multicolumn{4}{|l|}{ Gender } \\
\hline Male & $50 \%$ & $28 \%$ & 0.069 \\
\hline Female & $50 \%$ & $72 \%$ & \\
\hline $\begin{array}{l}\text { BCVA } \\
(\log \text { MAR) }\end{array}$ & $0.17 \pm 0.16$ & $0.20 \pm 0.20$ & 0.703 \\
\hline MRSE (D) & $0.37 \pm 2.50$ & $-1.19 \pm 3.96$ & 0.101 \\
\hline $\begin{array}{l}\text { Cataract } \\
\text { density }\end{array}$ & $2.00 \pm 0.86$ & $2.04 \pm 1.02$ & 0.964 \\
\hline $\begin{array}{l}\text { Pupil size } \\
(\mathrm{mm})\end{array}$ & $4.60 \pm 0.57$ & $4.72 \pm 0.56$ & 0.495 \\
\hline $3 \mathrm{cpd}$ & 1.139 & 1.237 & 0.491 \\
\hline \multicolumn{4}{|l|}{ Photopic } \\
\hline $6 \mathrm{cpd}$ & 1.222 & 1.238 & 0.979 \\
\hline \multicolumn{4}{|l|}{ Contrast } \\
\hline $12 \mathrm{cpd}$ & 0.685 & 0.709 & 0.893 \\
\hline \multicolumn{4}{|l|}{ Sensitivity } \\
\hline 18 сpd & 0.227 & 0.233 & 0.726 \\
\hline Total HOA & $0.39 \pm 0.11$ & $0.46 \pm 0.20$ & 0.742 \\
\hline $\begin{array}{l}\text { Total } \\
\text { astigmatism }\end{array}$ & $0.57 \pm 0.05$ & $0.68 \pm 0.27$ & 0.051 \\
\hline \multicolumn{4}{|c|}{ Wavefront measurement } \\
\hline Total coma & $0.18 \pm 0.03$ & $0.23 \pm 0.18$ & 0.950 \\
\hline $\begin{array}{l}\text { Spherical } \\
\text { aberration }\end{array}$ & $0.20 \pm 0.03$ & $0.17 \pm 0.18$ & 0.540 \\
\hline $\begin{array}{l}\text { Other } \\
\text { aberrations }\end{array}$ & $0.25 \pm 0.12$ & $0.29 \pm 0.14$ & 0.165 \\
\hline
\end{tabular}

Abbreviations: cpd, cycles per degree; CVA, best-corrected visual acuity; $\mathrm{D}$, diopter; $\mathrm{HOA}$, high-order aberrations; logMAR, logarithm of the minimum angle of resolution; MRSE, manifest refraction spherical equivalent.

"Wilcoxon signed-rank test.

† Student's $t$-test.

${ }^{\ddagger} \chi^{2}$ test.

( $P=0.018$, Wilcoxon rank-sum test). When evaluating BCVA over time, no differences between the groups were found. Pupil sizes for the AcrysofIQ and AcrysofSingle-Piece groups were $4.39 \pm 0.46$ and $4.47 \pm 0.58 \mathrm{~mm}$ at $1 \mathrm{month}$, and $4.33 \pm 0.55$ and $4.32 \pm 1.60 \mathrm{~mm}$ at 3 months, respectively. No statistical significant differences were noted at both time points when comparing both groups $(P=0.513$ and $P=0.393$, Wilcoxon rank-sum test).

Change in contrast sensitivity showed a significantly greater increase in the AcrysofIQ group than in the AcrysofSingle-Piece group at 1 month in spatial frequencies 3 ( $P=0.023$, Wilcoxon rank-sum test), $6(P=0.048$, Student's $t$-test $)$, and $12(P=0.028$, Wilcoxon 


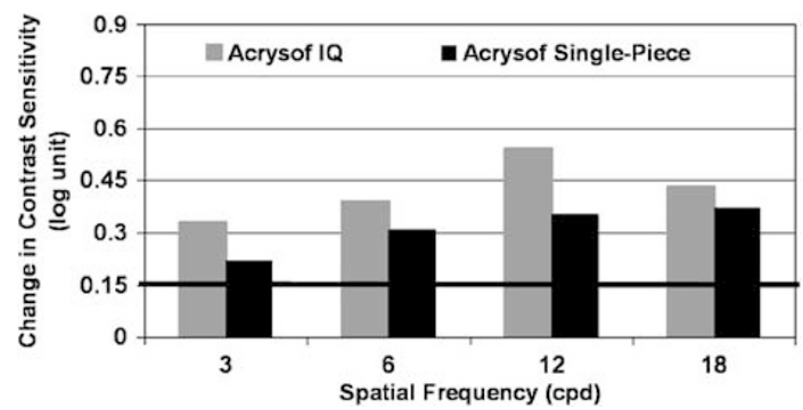

Figure 1 Change in contrast sensitivity preoperative to 1 month AcrysofIQ ( $n=28$ eyes) and AcrysofSingle-Piece ( $n=25$ eyes).

rank-sum test) (Figure 1); and in spatial frequency 3 $(P=0.037$, Wilcoxon rank-sum test $)$ and $6(P=0.048$, Wilcoxon rank-sum test) cycles per degree (cpd) at 3 months (Figure 2). However, no statistical differences among the groups at 1 and 3 months postoperatively were found at any spatial frequency.

Total HOA root mean square (RMS) significantly decreased in the AcrysofIQ group at $1(0.30 \mu \mathrm{m}, 20.5 \%$ reduction $)$ and $3(0.29 \mu \mathrm{m}, 23.1 \%$ reduction $)$ months when compared to baseline $(0.39 \mu \mathrm{m}, P=0.003$, KruskalWallis test), whereas it did not change significantly in the AcrysofSingle-Piece (Baseline, $0.46 \mu \mathrm{m} ; 1$ month, $0.40 \mu \mathrm{m}$ (10.5\% reduction); and $0.45 \mu \mathrm{m}$ ( $2.2 \%$ reduction) at 3 months, $P=0.889$, Kruskal-Wallis test). Differences between the two groups at both postoperative visits were statistically significant $(P=0.016$, Wilcoxon signed-rank test, and $P=0.0001, t$-test, respectively). Similarly, the reduction of postoperative SA was significant in the AcrysofIQ group at 1 (65.0\%) and 3 months (60.0\%) $(P<0.0001$, Kruskal-Wallis test), while it increased significantly in the AcrysofSingle-Piece group at $1(58.8 \%)$ and 3 months $(58.8 \%)(P=0.012$, KruskalWallis test) when compared to baseline. When comparing SA between groups, a significant difference at $1(P<0.0001$, Wilcoxon signed-rank test) and 3 months $(P<0.0001, t$-test) was evident (Figure 3$)$. In the AcrysofIQ group, we found a decrease in SA of 65.0 and $60 \%$ at 1 and 3 months after surgery, respectively, while SA increased by $58.8 \%$ in the AcrysofSingle-Piece group in both postoperative visits.

There were no significant differences in total astigmatism, total coma and other terms among the groups, or compared to preoperative values.

The results of the questionnaire are summarized in Table 2. The overall VFQ score included all the dimensions evaluated in the questionnaire; however, just the dimensions related to vision were analysed and included in the table. Preoperatively, patients in the AcrysofIQ group had significantly lower scores than the AcrysofSingle-Piece group in the following dimensions: overall score ( $P=0.02$, Wilcoxon rank-sum test), near

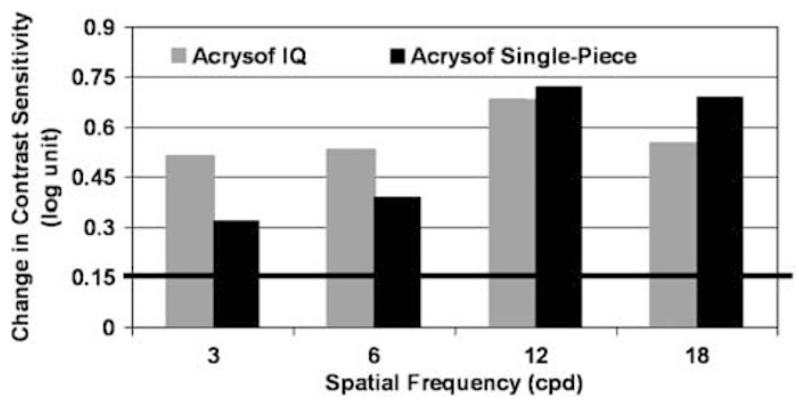

Figure 2 Change in contrast sensitivity preoperative to 3 month AcrysofIQ ( $n=28$ eyes) and AcrysofSingle-Piece ( $n=25$ eyes).

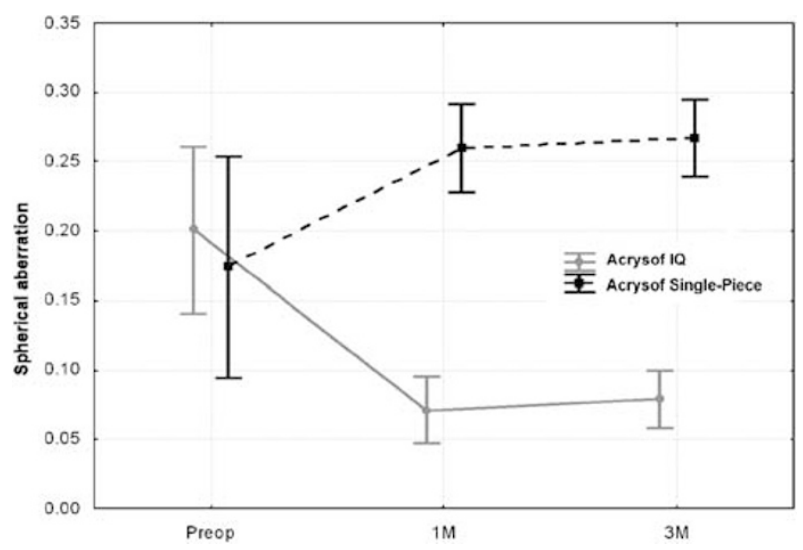

Figure 3 Spherical aberration comparison per group over time.

Table 2 VFQ-25 questionnaire responses (mean score) over time

\begin{tabular}{llll}
\hline & Baseline & 1 month & 3 months \\
\hline Overall VFQ & & & \\
AcrysofIQ & $70.3 \pm 13.3$ & $87.0 \pm 11.0$ & $87.7 \pm 10.9$ \\
AcrysofSingle-Piece & $80.4 \pm 9.2$ & $89.6 \pm 5.3$ & $90.3 \pm 3.7$ \\
& & & \\
General vision & & & \\
AcrysofIQ & $61.4 \pm 13.8$ & $82.9 \pm 14.4$ & $87.5 \pm 11.9$ \\
AcrysofSingle-Piece & $65.4 \pm 14.2$ & $85.8 \pm 12.4$ & $87.0 \pm 9.2$ \\
& & & \\
Distance activities & & & \\
AcrysofIQ & $66.4 \pm 17.7$ & $89.8 \pm 10.9$ & $90.0 \pm 10.4$ \\
AcrysofSingle-Piece & $78.6 \pm 15.2$ & $88.7 \pm 11.6$ & $91.3 \pm 10.3$ \\
Near activities & & & \\
AcrysofIQ & $61.0 \pm 16.1$ & $83.9 \pm 13.9$ & $86.3 \pm 14.7$ \\
AcrysofSingle-Piece & $79.2 \pm 11.8$ & $88.2 \pm 10.4$ & $90.0 \pm 10.4$ \\
& & & \\
Color vision & & & \\
AcrysofIQ & $87.5 \pm 19.0$ & $92.9 \pm 11.7$ & $95.5 \pm 9.3$ \\
AcrysofSingle-Piece & $94.2 \pm 11.0$ & $97.9 \pm 7.2$ & $97.5 \pm 7.9$ \\
& & & \\
Driving & & & \\
AcrysofIQ & $54.8 \pm 23.0$ & $87.3 \pm 14.9$ & $84.0 \pm 15.3$ \\
AcrysofSingle-Piece & $73.3 \pm 11.4$ & $84.8 \pm 8.4$ & $90.0 \pm 9.5$ \\
\hline
\end{tabular}

AcrysofIQ, $n=14$ subjects; AcrysofSingle-Piece, $n=13$ subjects. 
Table 3 Literature review of studies evaluating aspheric and spherical intraocular lenses

\begin{tabular}{|c|c|c|c|c|c|c|}
\hline \multirow[t]{2}{*}{ Author } & \multirow[t]{2}{*}{ Compared IOLs } & \multicolumn{5}{|c|}{ Measured outcomes } \\
\hline & & $B C V A$ & Photopic contrast sensitivity & Mesopic contrast sensitivity & Total HOA & $S A$ \\
\hline Belluci et $a l^{5}$ & Tecnis \& SA60AT & $\begin{array}{l}\text { Tecnis significantly } \\
\text { better }\end{array}$ & $\begin{array}{l}\text { Tecnis significantly better in } \\
\text { all spatial frequencies except } \\
1.5 \mathrm{cpd}\end{array}$ & $\begin{array}{l}\text { Tecnis significantly better in } \\
\text { all spatial frequencies except } \\
1.5 \mathrm{cpd}\end{array}$ & $\mathrm{N} / \mathrm{E}$ & $\mathrm{N} / \mathrm{E}$ \\
\hline Mester $e t a l^{6}$ & Tecnis \& SI-40 & $\begin{array}{l}\text { Tecnis significantly } \\
\text { better }\end{array}$ & $\begin{array}{l}\text { Tecnis significantly better all } \\
\text { spatial frequencies at } 3 \text { months. }\end{array}$ & $\begin{array}{l}\text { Tecnis significantly better all } \\
\text { spatial frequencies at } 3 \text { months. }\end{array}$ & $\mathrm{N} / \mathrm{E}$ & $\begin{array}{l}\text { Significantly higher } \\
\text { in SI-40 group. }\end{array}$ \\
\hline Packer $e a^{7}$ & $\begin{array}{l}\text { Tecnis \& Sensar } \\
\text { OptiEdge }\end{array}$ & No difference & $\begin{array}{l}\text { Tecnis significantly better at } \\
3 \text { and } 6 \mathrm{cpd}\end{array}$ & $\begin{array}{l}\text { Tecnis significantly better at } \\
1.5,3 \text { and } 6 \mathrm{cpd}\end{array}$ & $\mathrm{N} / \mathrm{E}$ & $\mathrm{N} / \mathrm{E}$ \\
\hline Kennis et $a l^{9}$ & $\begin{array}{l}\text { Tecnis, Sensar \& } \\
\text { SN60AT }\end{array}$ & No difference & $\begin{array}{l}\text { Tecnis significantly better at } \\
\text { all spatial frequencies except } \\
1.5 \mathrm{cpd}\end{array}$ & $\begin{array}{l}\text { Tecnis significantly better at } \\
\text { all spatial frequencies except } \\
1.5 \mathrm{cpd}\end{array}$ & $\mathrm{N} / \mathrm{E}$ & $\mathrm{N} / \mathrm{E}$ \\
\hline $\begin{array}{l}\text { Martinez-Palmer } \\
\text { et al }\end{array}$ & Tecnis \& SA60AT & $\begin{array}{l}\text { Significantly better } \\
\text { in Tecnis group }\end{array}$ & $\mathrm{N} / \mathrm{E}$ & No difference & $\mathrm{N} / \mathrm{E}$ & $\mathrm{N} / \mathrm{E}$ \\
\hline Muñoz et $a l^{11}$ & $\begin{array}{l}\text { Tecnis, Sensar } \\
\text { \& Stabibag }\end{array}$ & No differences & No differences & No differences & $\mathrm{N} / \mathrm{E}$ & $\begin{array}{l}\text { Significantly lower } \\
\text { in Tecnis group }\end{array}$ \\
\hline $\begin{array}{l}\text { Maia Rocha } \\
\text { et } a l^{12}\end{array}$ & $\begin{array}{l}\text { Acrysof IQ, } \\
\text { SN60AT \& Sensar }\end{array}$ & No differences & No differences & IQ significantly better at $3 \mathrm{cpd}$ & $\begin{array}{l}\text { Significantly } \\
\text { lower in IQ } \\
\text { group }\end{array}$ & $\begin{array}{l}\text { Significantly lower } \\
\text { in } \\
\text { IQ group }\end{array}$ \\
\hline Kasper et $a l^{13}$ & Tecnis \& Sensar & No difference & No difference & No difference & $\begin{array}{l}\text { No } \\
\text { difference }\end{array}$ & $\begin{array}{l}\text { Significantly lower } \\
\text { in Tecnis group }\end{array}$ \\
\hline
\end{tabular}

Abbreviations: BCVA, best-corrected visual acuity; cpd, cycles per degree; HOA, high-order aberrations; IOLs, intraocular lenses; N/E, not evaluated; SA, spherical aberration 
activities ( $P=0.005$, Wilcoxon rank-sum test), and driving $(P=0.01, t$ test). At 1 and 3 months, the differences between the groups were not statistically significant. Comparison within the AcrysofIQ group at months 1 and 3 to baseline showed a significant increase in the overall score $(P=0.02)$, general vision $(P=0.002)$, distance activities $(P=0.02)$, near activities $(P<0.0001)$, and driving $(P<0.0001)$. In the AcrysofSingle-Piece group, there was a significant increase in the overall score $(P=0.001)$, general vision $(P=0.008)$, and driving $(P=0.001)$. The increase in colour vision score was not significant in either group.

\section{Discussion}

Advances in IOL technology using wavefront analysis include modifications on its surface to improve visual outcomes. It has been reported that aspheric IOLs compensate the SA of the cornea and improve contrast sensitivity providing patients with better quality of vision. ${ }^{4-6}$ However, centration and tilting of the lens are important factors to control to obtain such results. ${ }^{7}$ The asphericity of the AcrysofIQ IOL has been created by reducing the posterior center thickness without increasing the lens-edge thickness and introduces $-0.20 \mu \mathrm{m}$ of SA compensating for the SA of the normal cornea. The first available aspheric IOL was the Tecnis (Advanced Medical Optics, Santa Ana, CA, USA) that has a modified prolate anterior surface design and adds $-0.27 \mu \mathrm{m}$ of SA into the eye to compensate for the corneal SA.

Table 3 summarizes the results of peer-reviewed published trial results from the literature comparing aspheric and spherical IOLs. ${ }^{5-11}$ The majority of these studies evaluated the Tecnis IOL and report better optical quality with aspheric IOLs that provided better contrast sensitivity under photopic and mesopic conditions.

There was a higher percentage of patients who achieved UCVA of 20/20 at 1 and 3 months in the AcrysofIQ group compared to the AcrysofSingle-Piece. The difference between the two groups in UCVA can be explained by variation in postoperative MRSE, even though the target refraction was the same in both the groups. On the basis of these results, adjustments to the constant used to calculate the AcrysofSingle-Piece IOL power were made to improve the visual outcomes.

Similar to previous studies, ${ }^{11-13}$ we did not find significant differences in photopic contrast sensitivity among the groups; however, there was a greater increase in the change of contrast sensitivity preoperative to 1 and 3 months in the AcrysofIQ group (Figures 2 and 3) compared to the AcrysofSingle-piece.

There was a greater reduction in total HOA in the AcrysofIQ group in all postoperative visits in the AcrysofSingle-Piece compared to the AcrysofSingle-
Piece. Furthermore, we found a greater decrease in SA at 1 and 3 months after surgery in the AcrysofIQ group, while SA increased AcrysofSingle-Piece group in both the postoperative visits. Mester and colleagues ${ }^{6}$ reported similar results. It is to be noted that we used a larger pupil size $(5 \mathrm{~mm})$ for aberration analysis compared to the $4 \mathrm{~mm}$ that they used. The results of our study are similar to those reported by Maia-Rocha and coworkers ${ }^{12}$ in their study comparing the AcrysofIQ to the AcrysofNatural and Sensar using 4 and $5 \mathrm{~mm}$ pupil sizes; the total HOA and SA were significantly lower in the AcrysofIQ group. Kasper et $a l^{13}$ also reported significantly lower SA comparing Tecnis and Sensar for physiological mesopic pupil of 3.84 and $3.76 \mathrm{~mm}$, respectively.

None of the aforementioned studies evaluated subjective functional vision. The results of the VFQ-39 questionnaire show that there was a significant increase in patient satisfaction in the AcrysofIQ group in distant and near activities. However, the differences between the groups were not significant at any time. Both the groups showed a significant increase in overall score, general vision, and driving.

Limitations of our study include comparing AcrysofSingle-Piece, which does not have the blue lightfiltering chromophore that characterizes the SN IOL series; however, different intra-individual comparison studies have shown no differences in visual acuity outcomes, contrast sensitivity, or colour perception between the AcrysofSingle-Piece and AcrysofNatural (SN60AT, Alcon Laboratories, Ft. Worth, TX, USA). ${ }^{14,15}$ The lack of contrast sensitivity measured under mesopic conditions is another limitation of this study. A study to compare the contrast sensitivity under mesopic conditions after surgery is underway. Difference in the postoperative MRSE is another limitation of the study when evaluating UCVA and the results of the subjective questionnaire as well as the preoperatively significant difference in some dimensions of the VFQ-39 questionnaire, specifically in near activities, driving, and overall score.

In summary, use of the aspheric acrylic AcrysofIQ lens, designed to compensate for the SA of the cornea and the lens, may improve the quality of vision of pseudophakic patients by reducing the total HOA and SA.

\section{Acknowledgements}

This work was supported in part by NIH/NEI EY-014793; an unrestricted educational grant to Magill Research Center MUSC-SEI from Alcon Laboratories, Ft. Worth, TX, USA; and an unrestricted grant to MUSC-SEI from Research to Prevent Blindness, New York, NY, USA.

Disclosure: HP Sandoval, none; LEF de Castro, none, DT Vroman, none; KD Solomon, Consultant to Alcon. 


\section{References}

1 Mela E, Gartaganis S, Koliopoulos J. Contrast sensitivity function after cataract extraction and intraocular lens implantation. Doc Ophthalmol 1996; 92: 79-91.

2 Wang L, Santaella RM, Booth M, Koch DD. Higher-order aberrations from the internal optics of the eye. J Cataract Refract Surg 2005; 31: 1512-1519.

3 He JC, Gwiazda J, Thorn F, Held R. Wave-front aberrations in the anterior corneal surface and the whole eye. J Opt Soc Am A Opt Image Sci Vis 2003; 20: 1155-1163.

4 Packer M, Fine IH, Hoffman RS. Wavefront technology in cataract surgery. Curr Opin Ophthalmol 2004; 15: 56-60.

5 Bellucci R, Scialdone A, Buratto L, Morselli S, Chierego C, Criscuoli A et al. Visual acuity and contrast sensitivity comparison between Tecnis and AcrySof SA60AT intraocular lenses: a multicenter randomized study. J Cataract Refract Surg 2005; 31: 712-717.

6 Mester U, Dillinger P, Anterist N. Impact of a modified optic design on visual function: clinical comparative study. J Cataract Refract Surg 2003; 29: 652-660.

7 Packer M, Fine IH, Hoffman RS, Piers PA. Improved functional vision with a modified prolate intraocular lens. J Cataract Refract Surg 2004; 30: 986-992.

8 Altman GE, Nichamin LD, Lane SS, Pepose JS. Optical performance of 3 intraocular lens designs in the presence of decentration. J Cataract Refract Surg 2005; 31: 574-585.

9 Kennis H, Huygens M, Callebaut F. Comparing the contrast sensitivity of a modified prolate anterior surface IOL and of two spherical IOLs. Bull Soc Belge Ophtalmol 2004; 294 49-58

10 Martinez Palmer A, Palacin Miranda B, Castilla Céspedes M, Comas Serrano M, Punti Badosa A. Spherical aberration influence in visual function after cataract surgery: prospective randomized trial. Arch Soc Esp Oftalmol 2005; 80: 71-77.

11 Muñoz G, Albarrán-Diego C, Montés-Micó R, RodriguezGalietero A, Alio JL. Spherical Ab Spherical aberration and contrast sensitivity after cataract surgery with the Tecnis Z9000 intraocular lens. J Cataract Refract Surg 2006; 32: 1320-1327.

12 Rocha KM, Soriano ES, Chalita MR, Yamada AC, Bottos K, Bottos J. Wavefront analysis and contrast sensitivity of aspheric and spherical intraocular lenses: a randomized prospective study. Am J Ophthalmol 2006; 142: 750-756.

13 Kasper T, Bühren J, Kohnen T. Visual performance of aspherical and spherical intraocular lenses: intraindividual comparison of visual acuity, contrast sensitivity, and higher-order aberrations. J Cataract Refract Surg 2006; 32: 2022-2029.

14 Mayer S, Wirbelauer C, Pham DT. Functional results after intraocular lens implantation with or without blue light filter: an intraindividual comparison. Klin Monatsbl Augenheilkd 2006; 223: 142-146.

15 Rodriguez-Galietero A, Montes-Mico R, Munoz G, Albarran-Diego C. Comparison of contrast sensitivity and color discrimination after clear and yellow intraocular lens implantation. J Cataract Refract Surg 2005; 31: 1736-1740. 